\title{
CONTRIBUIÇÕES DE MAX WEBER AO OLHAR SOCIOLÓGICO'
}

Elsio Lenardão

Professor do Departamento de Ciências Sociais da UEL

\section{Resumo}

O texto que segue é a exposição de uma proposta de aula introdutória à Sociologia de Max Weber (1864-1920), voltada ao aluno do ensino médio. Por meio do exemplo, indica-se uma possibilidade de exercício a ser desenvolvido pelo professor responsável pela disciplina neste nível de ensino. É uma tentativa de auxiliá-lo na tarefa de levar aos alunos a riqueza das contribuições weberianas, neste caso, algumas premissas e conceitos cujos conteúdos têm sido, muitas vezes, negados aos jovens pelo fato de o professor considerar sua explicação muito trabalhosa. São utilizados vários exemplos (através de charge, artigos de jornal e revista) da vida cotidiana que ilustram algumas daquelas premissas e conceitos.

Palavras-Chave: ensino médio; sociologia; Max Weber.

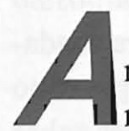

metodologia weberiana e suas aplicações são um grande estímulo ao desenvolvimento no aluno daquilo que Wright Mills chamou de a "imaginação sociológica", quer dizer, a capacidade de compreender como sua vida cotidiana está ligada a outros níveis mais

\footnotetext{
1 Comunicação apresentada em 2002 ao grupo de professores do ensino médio que ministram aulas de Sociologia e que participam das atividades de capacitação promovidas pelo Laboratório de Ensino de Sociologia, vinculado ao Departamento de Ciências Sociais da Universidade Estadual de Londrina.
} 
elevados da organização social e aos processos mais globais de toda a sociedade. O desenvolvimento desta forma de imaginação, permite ao indivíduo perceber que os problemas pessoais que tem com o que o rodeia estão ligados a questões gerais da estrutura social; que a sua história pessoal (biografia) é moldada pelo que acontece à sua sociedade (história); que, para compreender o que lhe está acontecendo, os homens têm de se considerar como simples pontos de intercepção da biografia e da história dentro da sociedade (WORSLEY, 1983, p.69-70) (grifado no original).

As análises de Weber permitem vislumbrar como boa parte das ações dos indivíduos são realizadas mirando os outros indivíduos, como há entre eles grande reciprocidade de intenções e expectativas, revelando a dimensão social do comportamento humano. Quer dizer que podemos compreender as ações de outros homens, que elas podem ser desveladas. Parte da metodologia weberiana demonstra que para conhecer o comportamento coletivo não basta considerar a legislação que o enquadra, o tipo de Estado que o conforma, tampouco basta verificar como se dá a divisão entre as classes e quais os interesses de classe que as mobilizam. Weber não ignora que há forças externas, objetivas, que participam da modulação do comportamento humano, como, por exemplo, quando reflete sobre o poder e diz que: "poder significa a probabilidade de impor a própria vontade, dentro de uma relação social, mesmo contra toda resistência e seja qual for o fundamento dessa probabilidade [...]" (WEBER apud CASTRO, 1997, p.31) (grifo nosso)

Na sua obra A Ética Protestante e o Espírito do Capitalismo encontram-se reflexões que insinuam um Weber que considera fundamental a força de coerção das estruturas sociais, bem menos próximo do método "individualista", como supõem certas interpretações sobre sua teoria. Escreve, por exemplo, que a "[...] moderna ordem econômica e técnica ligada à produção em série através da máquina, $[. .$.$] atualmente$ determina de maneira violenta o estilo de vida de todo o indivíduo nascido sob esse sistema [...]" (WEBER, 1999, p.130-131) (grifo nosso).

Mas observações desse calibre não seriam sua maior contribuição à Sociologia. Ao contrário, é aquela parte de sua metodologia que 
atenta mais para a conduta humana concreta e para a participação do indivíduo na construção do comportamento coletivo, ou seja, das relações sociais, diria ele, que oferece uma riquíssima contribuição ao desenvolvimento da "imaginação sociológica". Weber propõe que a Sociologia seja capaz de revelar as intenções que estão por trás dos comportamentos dos indivíduos. É este viés de seu método que merecerá aqui algumas anotações que intentam explicá-lo didaticamente.

\section{Sobre o objeto especial de análise das Ciências Sociais: o significado da ação humana}

De acordo com Weber "[...] o conhecimento dos fenômenos culturais é inconcebível, exceto sobre a base da significação que as constelações concretas da realidade têm para nós em certas situações particulares concretas" (WEBER apud ZEITLIN, 1973, p.132133) (grifado no original/tradução nossa). Ou seja, o pesquisador das Ciências Sociais se concentra na particularidade característica da realidade em estudo. Mesmo que sejam necessárias proposições teóricas gerais, pressupostos (por exemplo, "tipos ideais") sobre os fenômenos, o que sem dúvida tem grande valor heurístico, a compreensão da realidade exige que sua "particularidade" seja revelada. E, quem a dá é o conjunto de significados que tecem o conteúdo do fenômeno em foco. Por exemplo: podemos ter uma teoria geral (uma tipologia, diria um weberiano) sobre o voto nas sociedades capitalistas, que pressupõe relações plausíveis entre posição de classe e voto, sexo e voto, idade e voto, etc. Apesar de ser indispensável a uma investigação a existência desses pressupostos gerais (teoria geral prévia), eles não garantem a compreensão da realização concreta de uma dada situação eleitoral. Será preciso ir além do entendimento permitido pelas formulações teóricas gerais iniciais e investigar os significados concretos e localizados dos votos previstos e/ou dados, conferindo até onde se aproximam ou se distanciam dos pressupostos gerais, da tipologia inicial. 
Esse procedimento revela uma valorização dos aspectos qualitativos dos fenômenos sociais em relação aos quantitativos. Não que Weber ignore a força das estruturas sociais sobre a ação dos indivíduos, ele sabe que um fenômeno social determinado para ser compreendido na sua especificidade exige que sejam revelados os "sentidos", os "significados" das ações sociais e das relações sociais que o estruturam. Ou seja, o que os indivíduos "querem", "almejam", "desejam", "visam", e quais valores expressam, exatamente, quando direcionam sua ação de votar num determinado partido ou personalidade?

Não bastaria supor, por exemplo, que é bem provável que o trabalhador vota no partido dos trabalhadores, que os católicos votem no PHS ou na Social Democracia Cristã, etc. Essa seria uma probabilidade teórica e até mesmo uma ação baseada na racionalidade. Mas só a análise individualizada das "intenções" de voto é que poderia permitir a verificação da concretização dessa probabilidade e dos possíveis "desvios" em relação a ela.

É comum ouvirmos afirmações "categóricas" e cheias de certezas como: "trabalhador vota em trabalhador" ou, "Fulano é o candidato dos evangélicos, o que lhe garante $\mathrm{n} \%$ de votos". Há "forças objetivas" (semelhanças de condições de vida, de interesses materiais, políticos; afinidade de crenças, influência corporativa, entre outras) que estimulam de fato essas possíveis relações. No entanto, não há garantias de que se realizem absolutamente, porque haveria também a presença de outras incontáveis influências e circunstâncias que concorrem para o desenho da direção que tomarão os indivíduos na escolha de seus atos de votar. Eventos conjunturais podem alterar aquelas "tendências objetivas"; também podem concorrer para isso alguma circunstância de comoção geral: uma catástrofe qualquer, a morte de uma personagem "de expressão" na conjuntura; uma campanha de marketing eficaz pode, por sua vez, embaralhar aquelas "tendências objetivas", etc. Quem não se lembra do espanto que tomou a esquerda brasileira em 1989, quando boa parte dos pobres e miseráveis do país, os famosos 'descamisados', deu preferência de voto para o candidato das classes dominantes, o Sr. Collor de Melo? Observe o artigo de jornal que segue: 
Nas rodarlas de entrevistas, além do aspecto social, os eleitores falaram na necessidade de uma polícia mais bem paga e preparada. Mas nada é mais criticado do que a presença de Marco Vinício Petrelluzzi na Secretaria de Segurança. "Ele é a pessoa mais criticada de São Paulo, de A a Z", diz a socióloga.

Do candidato do PT a governador, José Genoíno, a maior parte das elcitores ouvidos o considerou muito ligado ao Legislativo, scm experiência administrativa. Os entrevistados reconhecem, porém, o esforço do petista para apresentar-se como candidato, característica que nào vêem $\mathrm{em}$ outro possível concorrente, o também deputado e presiden- das as classes. Também é comum ans eleitores a idéia aumentar o número de vagas nas escolas e de hospitais e postos de saúde.

Outra queixa das classes C e D que passa longe das rodas de conversa A e B é sobre a habitação. Os pobres, em resumo, comentam que têm duas opçōes: ou vivem "amontoados" en uma única casa ou improvisam barracos para acomodar apenas a família. Já nas classes de alta renda, os assuntos giram em torno da necessidade de redução de impostos, para motivar empresários e criar emprego. Boa parte dos entrevistados defendeu incentivos fiscais do Estado para atrair novos empreendimentos.

LEAL, Luciana Nunes. Pesquisa indica perfil do candidato ideal em SP. O Estado de S. Paulo, São Paulo, 31 dez. 2001.

Ele mostra, através de uma investigação de tipo sociológica, como aparecem nas expectativas dos entrevistados, tanto a força das "condições objetivas" (posição de classe, por exemplo), como possibilidades de associações 'irracionais' entre "condições objetivas" e expectativas subjetivas, individuais, dos sujeitos. $\mathrm{O}$ artigo serve muito bem para demonstrar a realização, quer dizer, o "funcionamento". da premissa weberiana quanto à relevância da "intenção", do "significado" dos valores na orientação da ação humana.

Por outro lado, Weber não ignora a necessidade de, após "descortinadas as constelações concretas de significados de determinado evento social", situá-las dentro de grandes correntes de tendências sociais. Por exemplo, quando pensa a relação de influência geral entre a ética protestante e o capitalismo, ele o faz ao mesmo tempo que tenta compreender como, concretamente e com particularidades, essa relação se deu nos E.U.A, na Inglaterra e especialmente na 
Alemanha, onde teve de conviver, por um tempo mais longo que nos dois outros países, com o domínio político dos latifundiários e seus interesses materiais imediatos contrários àquela ética e às relações de produção de tipo capitalista.

\section{Ação social: definição e exemplo}

De acordo com Weber, a Sociologia pode ajudar a compreender a vida social esclarecendo como os homens organizam suas ações sociais. Por "ação social", Weber compreende "qualquer ação que o indivíduo faz orientando-se pela ação dos outros sendo dotada e associada a um sentido". Para ele, a "ação social", seria aquela marcada pelo seu "caráter subjetivo". Daí que interessaria à Sociologia "compreender a conduta social humana", revelando explicações das "causas" e "conseqüências" de sua origem. Quer dizer que seriam as "atitudes" que explicariam a "conduta social" dos indivíduos. Para compreendê-la seria preciso descobrir seus "sentidos", seus "motivos", suas inspirações e razões.

O termo "ação social" refere-se àquele comportamento humano que revela que o agente o carregou de significados, de sentidos culturais, como: ressentimento, aspirações, esperanças, decepções, sonhos, utopias, repulsas, ódios, etc. Enfim, tal "ação social" revela que os homens, ao contrário das rochas, das plantas ou das máquinas, pensam, valorizam e sentem. São portadores de "consciência". Quer dizer que o comportamento humano contém, na maioria das vezes, um elemento intencional. Assim, o trabalho de observar uma rocha, para a investigação que faz um geólogo, é bem diferente do trabalho de observar as ações humanas realizado por um cientista social. Nesse caso, é diverso porque os objetos têm diferenças acentuadas. É claro que o homem também tem comportamentos que exprimem mais puramente sua condição de animal, como, por exemplo, aqueles ligados às reações instintivas e aos estímulos físicos.

Portanto, a ação social, 
[...] é uma ação que leva em conta, ou é afetada, pela existência dos outros. Envolve a compreensão ou a interpretação do significado do seu comportamento - calculando o que os outros pensam, sentem ou tentam fazer: projectamo-nos nas mentes das outras pessoas. E, certamente, eles fazem exatamente o mesmo em relação ao nosso comportamento. Tem-se designado este processo recíproco por "dupla contingência". De maneira ainda mais complexa, prevemos o que os outros pensam de nós, etc. Isto não é uma complicação acadêmica e abstrata. É uma parte perfeitamente normal da vida quotidiana [...] (WORSLEY, 1983, p.58) (grifado no original).

Os quadrinhos abaixo (Lucy e Charlie Brown) ilustram com humor e clareza o fenômeno da "reciprocidade de significados" no comportamento humano.

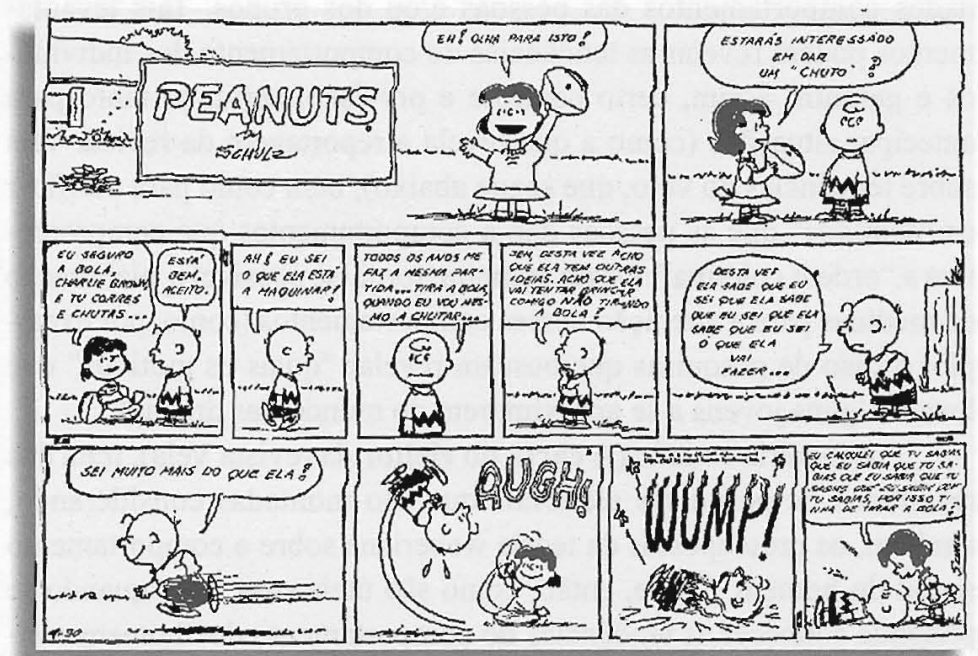

WERSEY, Peter. Introdução à Sociologia. Lisboa, Dom Quixote, 1983.

Considerar a importância do "sentido" na ação humana implica em observá-lo não só na iniciativa do homem, na iniciativa de sua ação individual, mas também considerá-lo como sentido já objetivado em instituições, na tradição e no costume, capazes de orientar numa mesma direção as ações dos indivíduos de um grupo. Daí, a religião e seus 
valores, sua ética, como objeto de estudo para Weber. Ele viu no protestantismo uma "fonte" de valores orientadores do comportamento, bastante adequada às necessidades da economia capitalista que se firmava na Europa nos séculos XVIII e XIX.

\section{Ação social: relevância prática}

Saber sobre as características da "ação social" torna possível desenvolver mecanismos de investigação que permitem apreciar a probabilidade do comportamento de uma pessoa ou de um grupo de pessoas. Isto é, podemos levantar os "significados", os "sentidos", as motivações que parecem inspirar num dado momento e lugar, determinados comportamentos das pessoas e/ou dos grupos. Tais levantamentos podem revelar as tendências do comportamento dos indivíduos e garantir, assim, certo controle e previsão, servindo tanto para antecipar situações (como a que revela a reportagem da revista Veja sobre tendências do voto, que segue abaixo), bem como para verificar os "sentidos" que as pessoas dão a comportamentos que comprometem a "ordem coletiva". Dessa maneira, torna-se possível a elaboração de medidas para a alteração desses comportamentos (como, por exemplo, o caso de pesquisas que buscam revelar "quais os motivos" que levam alguns jovens a se aproximarem do mundo das drogas).

A matéria ao lado (A carta do eleitor da revista Veja), trata dos resultados de pesquisas eleitorais que são montadas considerando, também, os pressupostos da teoria weberiana sobre o comportamento social do homem. Vê-se, então, como são úteis suas teses quando se pretende conhecer as tendências do comportamento do "homem-eleitor". O pressuposto básico que orienta essas pesquisas é o de que o "homem dá sentido à sua ação social: estabelece a conexão entre o motivo da ação, a ação propriamente dita e seus efeitos" (COSTA, 1987, p.63) Acrescente-se que o "motivo" (o objetivo) que está por trás da ação social revela o "sentido" dessa ação, e esse se revela, por sua vez, na sua gênese social, sempre que o agir de cada indivíduo leva em conta a resposta ou reação de outros indivíduos. 

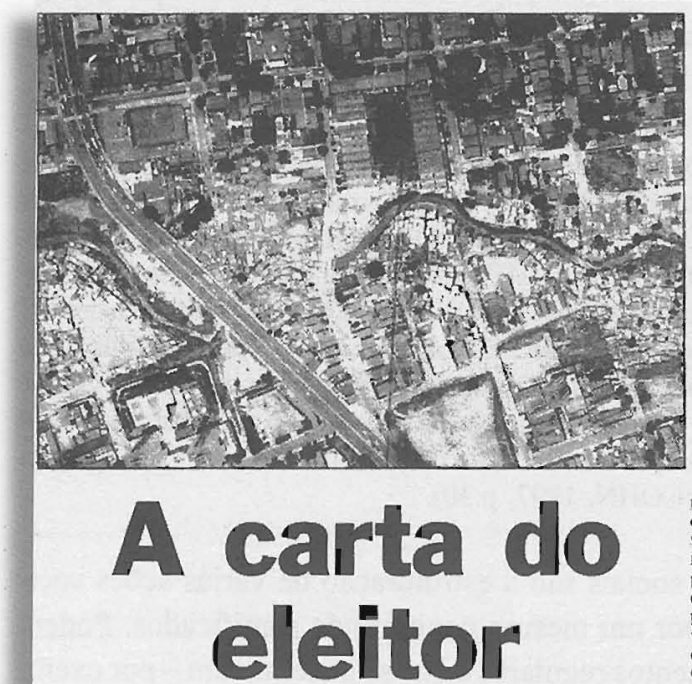

As pesquisas mostram que pobres, ricos e classe média gostam mesmo de obras - por motivos diversos

\section{Hâ uma precisão matemáti-} ca na briga dos candidasos pela preferencia do eleitorado. A um mês das eleiçōes, os concorrentes debrucam-se so bre gráficos, planilhas e tabelas de intençöes de votos. Perscrutam os desejos do eleitorado, escondidos atrás de vidros espelhados, de onde acompa nham as corversas de grupos de pessoas comuns que comentam a campanha municipal em troca de um sanduiche e um refrigerante. $\dot{E}$ ali, nas pesquisas qualitativas, que se descobre mais do que a preferéncia do eleitor. E posstvel apurar as motivafóes de seu voto. avaliar guais razóes poderiam fazê-lo nudar de apiniōo descobrir como anguntenta e como ouve argumentos.

No caso de São Paulo e Rio de Janeiro. onde há uma transfisão de votos dos prefeitos para seus afilhados, as pesqua.

28

sas também tentam mapear quais os pontos dos traballios de Paulo Majufe César Maia capazes de influenciar o eleitorado. À situaçăo, evidentemente, intenessam os acertos. A oposiçãa os erros. VEJA consultou essas pesquisas e entre. vistou seus onganizadores para caplicar de onde vem a enorme cesta de votos que os aruais prefeiros estão legando a Celso Pitta e Luiz Paulo Conde.

\section{O efeito tapume}

Paulo Maluf e Cessar Maia espalharam eanteiros de obras pela cidade e acerta. ram. De acordo com as pesquisas, a visão da cidade cheia de tapumes é o único espetáculo eleitoral que provoca alegria nos eleitores de todas as faixas salariais. "O Malut É obreiro mesmo", exclamou um eleitor, de classe média baixa, ouvido na Zona Leste, em Sào Paulo, há um
Adeus, favela

o Corrego Agua Espralada, na Zona Sul de SSio Paulo, tinha suas margers crivadas do berracos da favela do Buraco Quente. Na foto aterea ì esquerda, eles aparecem na cor
cinza. Tres anos depots, 15 000 famillas de favelados foram desalojadar - uma avenida com 4,5 quilometros de extenstä surgiu (foto id direita), a um custo de 160 milhbes do reais. Maluf ofereceu às familias que moravam no local abrizos provisbrios ou indenizacjes de atb 1500 reats - caminhâo do mudança para qualquer lugar do Brasill. Depois de poucos protestos, 3000 familias sairam de Silo Paulo. As demais

foram distribuldes pola cidade

mês. "Essa história de fazer coisa em educaçăo e em favela é s6 para cleitor ver: voto nele por causa das obras." Conforme se apura nesses grupos, a obra. para começar, mostra que a prefeitura está trabalhando. Faz bem à imagem do prefeito, que, graças a ela, passa a ser visto como uma autoridade dinåmica que quer o desenvolvimento da cidade Outra vantagern é que o eleitor pode até perceber que com o dinheiro de um túne o prefeito poderia ter feito vários quilômetros de merrô, mas dificilmente concluirá que o túnel é intutil, pois ele percebe que ajuda a melhorar o trânsilo. Isso faz com que o eleitor da periferia, que so anda de ônibus $e$ apenas conhece um túnel último tipo de fotografia - pois ali só se entra de automóvel - possa até gostar da obra. No Rio, o efeito tapume foi enorme. Luiz Paulo Conde subiu para - topo das pesquisas quando seu padrinho César Maia abriu as cortinas de cbras como o projeto Rio Cidade, com cartões-postais instalados em: Copacabana, Ipsnema e Leblon. Nas pesquisas. outro trunfo do prefeito César Maia foi construçăo da Linha Amarela. via expressa de 25 quilometros que ligarạ : Barra da Tijuca, na Zona Oeste, à liha do Fundāo, na Zona Norte, a um custo de 270 milhōes de reais. A Linha Amarela nem estí pronta, mas o balanço das pesquisas qualitativas mostra que o simple fato de ser uma obra de grandes proporcồes enche os olhos do eleitorado. que percebe que ali está sendo realizado um investimento importante, capaz de mudar a vida de muitas pessoas.

VEJA, 4 DE SETEMBRO, 1996

A Carta do Leitor. Veja, p. 23-30, set. 1996 
Vinculado ao conceito de "ação social" está o de "relação social". No limite é esta última, como objeto, que interessa à sociologia compreensiva weberiana, que assim é chamada porque se preocupa com o "como" acontece a "ação social" e não com o "por quê" acontece.

A relação social diz respeito à conduta de múltiplos agentes que se orientam reciprocamente em conformidade com um conteúdo específico do próprio sentido das suas ações. Na ação social, a conduta do agente está orientada significativamente pela conduta de outro ou outros, ao passo que na relação social a conduta de cada qual entre múltiplos agentes envolvidos (que tanto podem ser apenas dois e em presença direta quanto um grande número e sem contato direto entre si no momento da ação) orienta-se por um conteúdo de sentido reciprocamente compartilhado (COHN, 1997, p.30).

As "relações" sociais são a estruturação de várias ações sociais que se motivam por um mesmo conjunto de significados. Podem estruturar comportamentos regulares e que se generalizam - por exemplo, procedimentos em relação à vida conjugal, ou à relação de namoro - ou conformar-se numa "estrutura particular de relações sociais", materializando-se em instituições particulares - como, por exemplo, a família patriarcal, o código civil.

\section{A influência externa na produção dos sentidos da ação}

$\mathrm{Na}$ análise dos significados da ação é importante lembrar as influências exteriores que pesam sobre a ação, sobre o comportamento do homem. É preciso perscrutar a "origem", as fontes dos significados que orientam, que dão sentido às ações. Ou seja, não basta revelar o conteúdo dos sentidos das ações que organizam certos comportamentos em relação ao consumo ou ao lazer. Seria preciso também buscar revelar como se originam, como se constróem esses "sentidos", esses "desejos". Atente-se para os dois artigos que seguem. 


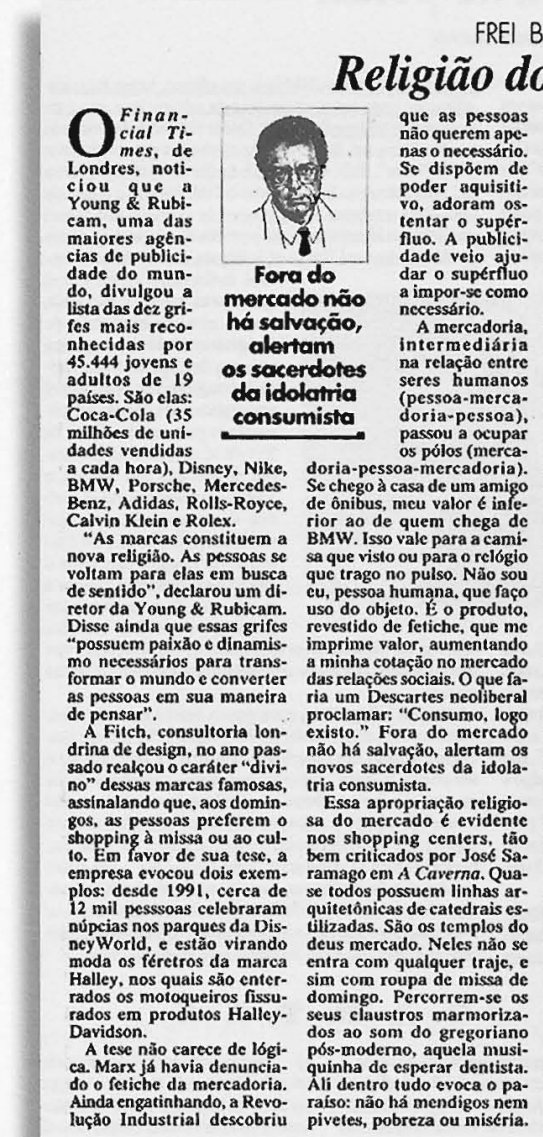

\section{REI BETTO}

O

Financial $r i$ nhecidas por 4.444 joysers

paises. Săo clas: milhóes de unidades vendidas

a cada hora), Disney, Nike, alvin Klein c Rolex.

As marcas constituem a

consultoria lono o fetiche da mercadoria. luçăa Industrial descobriu

pivetes, pobreza ou misćria.
Com olhar devoto, o consumidor contempla as capelas que ostentam, em rícos nichos, os veneráveis objetos de consumo, acolitados por belas sacerdotisas. Quem pode pagar a vista se sente no céviquem recorre ao cheque especial ou ao crediario no purgatorio: quem nāo dispur poe de recurso, no inferno Na saida, entretanto, todos se irmanam na mesa "cuca ristica" do McDonald's.

A Young \& Rubicam comparou as agências de publicidade aos missionários que difundiram pelo mundo relijiondiram pelo mundo religióes como o cristianismo e 0 islamismo. "As religiōes cram baseadas $\mathrm{cm}$ idcias poderosas que conferiam significado e objetivo à vida", de clarou o díretor da agéncia inglesa.

A fé imprime sentido subjetivo a vida objetivando na prática do amor, enquanto um produto cria apenas a to um produio cria apenas a
ilusoria sensação de que,

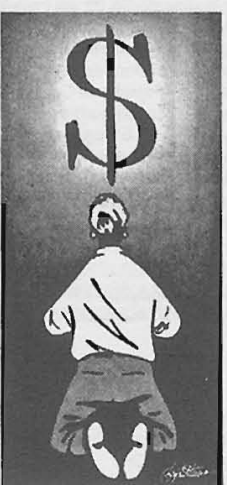

racas a cle, temos mais va or aos olhos alheios. $O$ consumismo é a doença da baixa auto-estima. Um Sảo Francisco de Assis ou Gandhi nảo necessitava de nenhum artificio para centrarse em si e descentrar-se nos outros $\mathrm{cm}$ Deus.

O peeado original dessa nova "rcligião" é que, ao contrário das tradicionais, ela não é altruísta, é egoísta; não favorece a solidaric dade, e sim a competitividade; năo faz da vida dom, mas posse. E o que es pior: acena com o paraiso na Teracenar ra c manda o consumidor para a eternidade completamente desprovido de todos os bens que acumulou deste lado da vida.

A crítica do fetiche da mercadoria data de oito séculos antes de Cristo conforme este texto do profeta loming a madeira, desenha a lápis uma figura, trabalha-a com o formato e aplica-lhe o com passo. Faz a escultura com medidas do corpo humano com rosto de homem, para que cssa imagem possa cs. que cssa imagem possa es (ar mo cedro. (...) O proprio escultor usa parte dessa madeira para es. quentar e assar seu pão; também fabrica um deus a diante dele se ajoelha (...) faz uma oração, dizendo: 'Salva-me, porque tu és o meu deus!'." (44, 13-17).

Da religiào do consum năo escapa nem o consumo da religiáa, apresentada como um remédio miraculoso, capaz de aliviar dores e angústias, garantir prosperidade $\mathrm{c}$ alegria. Enquanto isso "Ele tem fome c nä the dão de comer" ( The dân de

Feei Betto, esenilor, a aubs da mo mence Hotef Braat (Atica), entre ou. tros lirras

BETTO, Frei. Religião do Consumo. O Estado de S. Paulo, São Paulo, 21 mar. 2001 


\section{Cloaca do penta}

EUGENIO BUCA

ONFESSO que bebo Coca-Cola. Ao longo da minha existencia, devo ter tido as entranhas lavadas por uma Baia da Guanabara de Coca-Cola Um oceano de Coca-Cole. Um século de imperialismo de Coca-Cola. Eu obedeco as placas que ondenam "Beba Cocs-Cola". Eu bebo Coca-Cola. E é assim, dessa condigha de um animal que bebe Coca-Cola e que pela Coca.Cola é bebida que eu posso afirmar: eu tenho nojo dessa campanha da Coca-Cola em prol do Brasil na Copa do Mundo. Tenhonojo sobretudo desse $c 0$ mercial em que Pelk aparece suado, pinganda, com o uniforme do Sentos e, clano, bebendo Coca-Cola o Pelé be beCoca-Cola.

0 leitor, telespectador que t, hâ de ter visto a peç em questa. A clmera, no come. ca, mostra dois pes calcados em chuteiras, $O$ esquerdo pisa o ch§o. Odireito descans sobre uma bola de capotso. A clmern vai subindo vagarosa, num movimento de ascensio. Entra uma voz decla. mando uma pardfinase pace do "Pai Nosso". O texto da publicidade, cujo autor eu desconheço, faz um trocaditho de paicom pets, al go como "pes nossos que estais no chalo", seils, e assim segue a propaganda que, mesmo nâo sendo samba, evolui em feitio de oração. Surge o rosto do rei, suor no rosto, Coca nos Labias. Perfeicdo. A tampinhs de Coca-Cola entra em cena, entia, c, apenas para nào deixar a rima $\mathrm{em}$ " 20 ", tem o formato de um coraço. E lá vem o slogan, que tem algo a wer com paixa.o. É isso ali: a publicidade se apropria das core da banteira nacional, do Rei do futcbol e do "Pai Nouso" para construir o valor da marca que, nalo pur acaso, nada $1 \mathrm{em}$ de nacional, nem de esportiva e muito menos de catolica. É isso ai:eu sinto nojo.

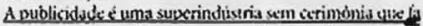
bricn sentidose simificacos pama vida wuzia dos suivilos de 3. piblico. Para nos Cadaum denossecompleta nos simos qu $\rightarrow$ Ellamentável, mas éa pura realidadebrasileira, como ainda discriminam \% os nordestinos. Mas eu gostaria de dixer queaquitem gente to competente quantoarnoSuL.

Ademir Lopes, Compina Grande ( $P B$ ) $\rightarrow$ Excelente a materia sobri a discriminaçodos nordestinus na TV. Jáéhorade os bons jornais comecarem a denunciar as injustiças sociais, indusive na

a TV. Em tempus de globalizaça, atuali.

a superindústria da publicidade nos oferece, Antes, essas sis nífcacós eram proporcionadas peta cultura: hoje sio confeccionadas na superindistria Quem sou eu? Antes, eu seria um brasileiro, um fa do Pelk, um cristio que gastava de rezar - "Pai Nosso". Hoje, eu sou um bebedor de Cocs-Cola, como um ralo, como um bueiro, como o Pelc. Por isso a marca da Coca-Cola tem tanto valor, porque ela se infiltra nos nocsos mecanismos identitarios, com o pendlo da expressilo, ecomo perdžo da rima em" " $\not 0 "$ ", e af, infiltrada, eta nos diz quem somos. Assim como a Nike, essa af que fibrica marca, e nło tinis, que $t$ uma superindistria do imaginário, e nāo uma empresa do ramo de calcados. Éessa lógica do imaginánio superindustrial que explica parte do gozo experimentado pelo sujeito diante da TY: de ve ali o sentido (fabricado) do que nāo tem sentido, 0 semido de si mesmo. Ele se pacifica 0 consumo das mercado. rias comeca, portanto, pelo consumo das imagens (das quais o sujeito precisa para se explicar a si mesmo). E o consumo das imagens, como se fosse trabalho. como se ver televistio fosse uma forma de trabalho, ainda que nào remunerado, é o que completa a fabricapio do valor das marcas.

Voltemos a Coca.Cola, coisa gasose que eu juro que bebo. Voltemos no tempo, tambem. Voltemos a 1957, ano em que Décio Pignatari, um pioneiro da critica de TV no Brasil. fer. seu poema "Cloaca", superconcretamente subversivo: "bebe coca colal babe cola/ beba cocal babe cola caco/ cacol cola/ cloaca". Se adjetivos aí fossem admitidos, poderiamıs dizer: supercloaca superindustrial. Voltemos, enfim, so juizo que munca tivemos. O imperativo "Beba Coca-Cola" entra assim nos deswlos da fé neligiosa, do patriotismo, da devocalo a uns rei, nem que seja un ri do fulebol. 6 cria seu valor. Cono se Bossemos todos idiotas, todos inimputáveis, todos obodientes bebedores de Coca-Cola. Éassime, noentanto, funciona.

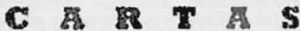

zaclo de mercado, essa baboscira toda ditada por um sistema falido e negligen tc, omais difficil $e f a l a r a$ tingua humans. Maria Lucia de Souza Navas, Campines(SP) $\rightarrow$ A mediocridade em que se encontra mergulhada TV impede que José Dumont, principalmentedepois de "Abril Despedacado", scja levadoà ele FazA-lo, seris o mesmo que atirax perolas asporcos.

Corlos Bruni Fernandes, Sa Paulb(SP) $\rightarrow$ Queria pedir aoSBT que reprisasse anovela "Carrosse". Acho que as criançasde hoje våo gostar! OSisT ea Globo também podiam mudar orepertóniode desenhosmatinais.

Glovano Negretros, Piracicaba (SP) $\rightarrow$ Se, conforme o TV Folhe (19/5), até os cubladoresconsideram as inadufros para TV nuins, por que as empresas não contratam uradutores melhores, diso a eles meis tempo, ou providencian revi.

BUCCl, Eugênio. Cloaca do Penta. Folha de S. Paulo, São Paulo, 9 ju. 2002. 
Os artigos nas páginas anteriores, do escritor Frei Beto e do jornalista Eugênio Bucci, tratam de como se poderia perceber a produção originária de certos "gostos", "desejos" e "significados" para eventos e comportamentos dos indivíduos dos dias de hoje. Para BUCCI e BETTO, a publicidade - item da indústria cultural contemporânea - é hoje a principal "fábrica de sentidos e significações para a vida" dos sujeitos, criando e moldando comportamentos. Ou seja, as imagens e as idéias que ela produz e que são assimiladas pelo público "se convertem em forças efetivas na história", diria Weber.

\section{0 tipo ideal}

Para facilitar a análise de casos concretos de fenômenos sociais e a possibilidade de compreender suas particularidades a partir da comparação com fenômenos parecidos mas situados noutro contexto, ou noutro tempo, Weber propõe o recurso de pesquisa reconhecido como "tipo ideal". Propõe que o investigador social que se dirige à compreensão de um fenômeno social o faça munido de uma "hipótese" bem apurada, "idealmente" apurada, sobre o que seria aquele fenômeno se pudesse apresentar-se de um modo "puro", "imaculado" e organizado racionalmente. Essa hipótese materializa-se em "quadros iniciais de referência" sobre o objeto em estudo, numa "noção prévia" que ajudará o investigador a orientar-se na apreensão daquilo que realmente "se liga" ao seu objeto de interesse, evitando que se perca no emaranhado de dados e variáveis que tocam seu objeto, sem serem, para seu caso, relevantes:

É buscando esse suporte de orientação que Weber, quando visa a entender como o capitalismo moderno se firmou primeiro na Europa e não em outras regiões, parte exatamente de uma "definição" clara do que entende por capitalismo, de uma definição que o "tipifica", que fornece um "quadro de referência" que lhe permite observar a ausência daquele tipo de capitalismo na China ou na Índia, por exemplo. E, por outro lado, sua existência nos E.U.A e na Inglaterra. Construiu, desse modo, um "quadro de referência" que apresenta o capitalismo, na sua forma típica, como, 
[...] uma organização econômica racional assentada no trabalho livre e orientada para um mercado real, não para a mera especulação ou rapinagem. O capitalismo promove a separação entre empresa e residência, a utilização técnica de conhecimentos científicos, o surgimento do direito e da administração racionalizados (COSTA, 1987, p.67).

Uma justificativa para o uso do recurso da tipologia dá-se, por exemplo, porque os fatos, os dados, que interessam ao cientista social, não podem ser recolhidos sem a existência prévia de uma concepção com o que recebem certa ordem, ganham organização e sentido. Quer dizer, os fatos não se ordenam por si mesmos e, até na mais simples das investigações, estão presentes hipóteses teóricas construídas primeiramente no espírito do investigador. Tais premissas sugerem as espécies de fatos e dados que o investigador deve procurar e quais delas são provavelmente relevantes ou irrelevantes e podem, por estas razões, ser aproveitadas ou desprezadas. Essas mesmas hipóteses teóricas prévias orientam, inicialmente, o investigador sobre quais as "causas prováveis" que deve procurar, quais as "conexões" que valem a pena ser estudadas, etc.

Esse procedimento é bastante evidente nas análises que os clássicos realizaram, como, por exemplo, nas pesquisas feitas por Durkheim. Este, mesmo quando analisava a tão conflituosa sociedade francesa do final do século XIX e início do XX, não deu importância às contradições de classe como uma causa relevante para a gravidade daqueles conflitos, priorizando, ao contrário, os fatos ligados a problemas como o do controle social e suas ligações com a moral social, com a solidariedade coletiva, enfim, com a harmonia social.

Um exemplo mais cotidiano sobre a seleção que um olhar munido de uma preparação prévia realiza, é dado pelo policial militar, que na sua ronda não deve olhar a realidade cotidiana como outra pessoa qualquer, mas sim de forma a procurar indícios que possam denotar a presença de delitos. A maioria de nós não vê o mundo prestando atenção à presença de criminosos potenciais. Mas a função do policial o leva a fazer isso mesmo: procurar elementos "significativos", como provas, vestígios, sinais, que revelem delitos ou crimes. Ou seja, nem todos os fatos com os quais se depara durante sua ronda são relevantes para o policial, muitas vezes não 
sãonem enxergados; importarão, mesmo, aqueles que tenham significado dentro do "quadro de referências" que o move, que o motiva. De certa forma, o uso do recurso do "tipo ideal" funciona com este objetivo: como "quadros de referência" que iluminam os fatos e dados que são relevantes e os que nã்o o são, num dado momento, para o investigador social.

\section{Exemplo de "funcionamento" da ação social e do recurso da tipologia social na produção do conhecimento}

Podemos, de modo simplificado, pensar no seguinte exemplo: quando nos preparamos para dar uma aula ou um curso qualquer, lembramos primeiramente do "público-alvo" ao qual se destina. É muito provável que, sabido qual é ele, recorramos às "noções prévias" que temos sobre esses públicos: sendo alunos do noturno de escola média da rede pública o grupo, terá determinado perfil, certas características comuns e gerais, que o marcam nas noções do imaginário mais divulgado. Se o público-alvo é de alunos de colégio privado, cujas mensalidades são altíssimas, também tentamos formular uma "noção prévia" sobre seu perfil de conjunto. Da mesma forma procederemos se o público-alvo for composto por professores de Sociologia oriundos do ensino médio da rede pública, e assim por diante. Essas "noções prévias" acabam por nos fornecer tipologias ("tipos ideais") sobre esses públicos. Fornecem-nos "quadros de referência" sobre eles, que servem para orientar a montagem de nossas aulas e cursos.

Porém, normalmente, somos cautelosos quanto à exatidão destes "quadros de referência" (tipos), sabendo que eles ajudam a conhecer antecipadamente algumas coisas sobre o público-alvo, mas nem todos os seus detalhes, as suas particularidades. Por isso, é comum que em seguida a esse primeiro raciocínio e também a partir dele busquemos informações mais detalhadas, mais minuciosas sobre as pessoas que compõem esse público-alvo, tentando levantar (através de uma ou outra conversa informal, ou mesmo alguns depoimentos) as expectativas de algumas pessoas desse público, o que esperam da aula/curso, o que desejam, do que não gostam, o que já sabem sobre o objeto abordado, etc. Procuramos, nesta 
etapa, um refinamento do conhecimento sobre esse público concreto, o que exige que caminhemos para além da 'noção prévia' (da tipologia) que tínhamos sobre ele, mas que ajudou a posicionarmo-nos e a olharmos inicialmente, já com certo cuidado, para nosso público-alvo.

\section{Referências}

CASTRO, Magali de. A análise do poder em instituições educacionais: a presença de Max Weber na sociologia da educação de Pierre Bourdieu. Educação em Revista, Belo horizonte, n 20/25, jun. 1997.

COHN, Gabriel. Weber: sociologia. São Paulo: Ática, 1997.

COSTA, Maria Cristina Castilho. Sociologia: introdução à ciência da sociedade. São Paulo: Moderna, 1987.

WEBER, Max. A ética protestante e o espírito do capitalismo. São Paulo: Pioneira, 1999.

WORSLEY, Peter. Introdução à sociologia. Lisboa: Publicações Dom Quixote, 1983.

ZEITLIN, Irving. Ideologia y teoria sociológica. Buenos Aires: Amorrortu Editores, 1973.

\section{Abstract}

The following text is the explanation of a suggestion of an introductory class to Max Weber's Sociology (1864 - 1920), focused on the Secondary Education student. Through the example, it is recommended a possibility of an exercise to be developed by the teacher who is responsible for that subject matter in this level of education. It is an attempt to help him/her with the task of introducing the students to the richness of Weber's contributions, such as, premises and concepts whose contents have been constantly denied to these students, due to the fact that the teacher considers his explanation too laborious. Several examples obtained from political cartoons, newspaper and magazine articles, based on the daily routine, are used to illustrate some of those premises and concepts.

Key words: secondary education; sociology; Max Weber. 


\section{Anexo \\ Para que serve a teoria da ação social ?}

Durante uma aula introdutória à Sociologia de Max Weber, certa aluna me surpreendeu com uma série de questionamentos a respeito da capacidade heurística da teoria da ação social, de maneira que me levou a um esforço maior para explicá-la através de exemplos. Segue a transcrição do que teria sido, mais ou menos, esse diálogo. Vale a pena fazê-lo porque é mais uma experiência de caminhos possíveis para iniciar uma aula sobre o sociólogo alemão.

Uma aluna, muito arguta, perguntou se a Sociologia podia 'prever' como votarão os brasileiros em outubro de 2002 .

Respondi que 'prever' talvez não, mas seria possível, sim, levantar as prováveis tendências de voto. Principalmente as tendências mais imediatas.

Ela continuou bastante curiosa, e acrescentou que seriam mais ou menos uns 115 milhões de votos. Como poderíamos saber o que se passa na cabeça de cada um? Como saber como cada brasileiro vai se comportar no cantinho reservado da urna?

Eu disse que não precisávamos questionar cada brasileiro, um por um, sobre como agiria no dia 3 de outubro e que bastava conhecer a previsão de comportamento de uma parcela desses 115 milhões, inclusive apenas uma pequena parcela. Isso porque a Sociologia sabe que, quando os indivíduos agem, eles agem com certo sentido, com certas expectativas, desejos, utopias, movidos por certos valores, etc. E, o mais instigante é que determinados grupos de indivíduos compartilham esses sentidos, expectativas, desejos e valores, de modo que boa parte de suas ações, de seu comportamento, é bem parecida, repete-se.

E ela me questionou novamente: - mas por que comungam as mesmas expectativas e desejos?

Respondi que a razão era simples. Já que vivem em grupos, em coletividades, torna-se necessário que se comportem, que ajam e reajam de maneira semelhante, garantindo assim a comunicação, a troca, o entendimento, o acerto nas relações que mantêm. Para os indivíduos do grupo saberem como se comportar sem ferir e magoar os demais é preciso que considerem, quer dizer, que de certo modo prevejam as reações daqueles. $\mathrm{Ou}$, noutros termos, é preciso que 'vejam a mente' dos outros indivíduos. Para ilustrar essas observações mostrei-lhe os quadrinhos do Charlie Brown (ver texto anterior). Enfim, têm que compartilhar conteúdos parecidos de expectativas, intenções, motivos e valores. Essa partilha permite a previsibilidade nas ações, logo, garantem que se estruturem relações sociais duradouras. 
E o voto do brasileiro? Insistiu a curiosa.

Disse-lle que no caso do ato de votar revelava-se com toda clareza a reciprocidade da ação dos indivíduos quando estão em grupos. Na situação de eleição, os indivíduos se baseiam na ação e na opinião de outros indivíduos para definir seu voto. Conversa-se com outras pessoas, lêemse revistas, jornais, vê-se tv, consultam-se pesquisas de opinião, etc. Quer dizer, o eleitor escolherá como agir na urna tomando como referência, e muito o comportamento e a opinião das outras pessoas. Essa necessidade de compartilhar opiniões cria "correntes de opinião", "conteúdos compartilhados de opinião" que revelam as direções, os sentidos prováveis daquelas ações individuais que se parecerão bastante nos meios e nos fins. Daí, mùnidos de instrumentos de pesquisa, podemos 'captar' partes representativas do conteúdo dessas "intenções de ação", desses "sentidos" do agir. Por isso é possível pesquisar as "intenções de voto" dos indivíduos em dado momento e em determinado lugar.

Sem me dar descanso, desafiou-me a curiosa: - Mas as pessoas não são exatamente iguais em muitos aspectos: há ricos, pobres e remediados, há empregados e desempregados, há homens e mulheres, letrados e analfabetos, etc. Sendo diferentes, votam do mesmo jeito?

Argumentei que todas as diferenças que ela havia lembrado devem influenciar também diferentemente nas ações dos indivíduos, aproximando os que compartilham características e distanciando os que não as compartilhasse. Mas que isso também não era tendência garantida $100 \%$. Por isso, na tentativa de levantar as "intenções" de voto, bem como as tendências de qualquer outra situação, deveríamos levar em conta essas 'diferenças' presentes entre os indivíduos que queremos conhecer, através de uma seleção de amostra que considerasse, por exemplo: renda, escolaridade, sexo, idade, local de moradia (cidade/campo), religião, etc. Com esse cuidado poderíamos garantir que o resultado de nossa pesquisa revelaria não só as tendências de voto, mas também como essas tendências variariam de acordo com aquelas diferenças.

Para ilustrar melhor o que eu vinha dizendo, convidei a 'curiosa' à leitura de duas matérias que apresentavam o resultado de pesquisas eleitorais e que revelavam bem o que discutíamos ( $1^{\circ}$ : Pesquisa indica perfil do candidato ideal em São Paulo e $2^{\circ}$ : A carta do eleitor - ver artigo anterior). A partir dessas duas matérias, mostrei também as possibilidades de entendimento do comportamento coletivo, levando em conta o pressuposto da ação com reciprocidade.

Não satisfeita, e testando minha resistência, a pequena curiosa avançou em suas dúvidas e questionou: - Já sabemos que dá pra ver as 'probabilidades mais prováveis' das intenções de voto, ou seja, dá mesmo para prever essas possibilidades mas, falta responder uma dúvida importante: quem ou o que fornece essas intenções, expectativas, desejos $e$ valores, para os indivíduos? $E$, quem os divulga, distribui, de maneira que quase todos ficam sabendo mais ou menos como os outros pensam? Cada um inventa seu conjunto de valores, divulga-o e espera que se espalhe, sendo assumido pelos outros? Ou seriam as religióes as produtoras de valores, desejos? Ou a televisão, quem sabe? Ah! Agora quero saber, como apareceram as primeiras "expectativas"? Como foram "socializadas"? 
Falei que seria difícil saber sobre a forma das primeiras relações sociais mas que certamente desde esse momento os homens combinaram regras, fundaram sonhos e desejos, dividiram obrigações e compromissos e toda essa tarefa deve ter-se consolidado como um conjunto de "sentidos" para a vida que organizavam juntos.

Hoje não seria diferente. Há várias obrigações, deveres, compromissos que os homens formam e mantêm durante o tempo e que aparecem, em boa parte das vezes, materializados nas instituições que organizam a sociedade em que vivem (leis, governo, família, escola, religião). Esses compromissos e obrigações sociais giram em torno de "valores" (o que é certo e errado, bom e ruim) sobre a vida em coletividade e podem reproduzir-se também por vias não institucionalizadas, como os costumes, a etiqueta, os modos, os hábitos, etc.

Quer dizer que, nesta dimensão da vida, o comportamento do indivíduo é formalmente previsto, porque é orientado, guiado (o caso do respeito à lei, é claro, como exemplo). Por certo que há desvios, mas se os há é porque há padrões de comportamento. Como as instituições e os costumes organizam a vida coletiva dando-lhe direção, uma parte das relações sociais fica institucionalmente orientada, ou seja, uma parte dos comportamentos está submetida a esta previsão.É uma garantia mínima da vida em grupo.

Acontece que, para essas obrigações, compromissos e os valores que as justificam funcionarem, é preciso que os indivíduos as assimilem, que as aceitem e as desejem. Isso quer dizer que elas (e aí incluem-se suas materializações: as instituições) não se mantêm se não forem 'realizadas' pelos indivíduos. Ao mesmo tempo que se impõem a eles, só existem porque eles as vivenciam individualmente nas relações sociais. Se não as desejarem mais, se disserem que 'não vêem mais sentido' nelas, elas se extinguem. Veja este exemplo: observa-se no Brasil (processo também comum a alguns outros países) que muitos jovens (em algumas regiões 4 de cada 10 , segundo o IBGE) já não querem viver a vida conjugal como 'manda' a santa madre igreja, como reza o modelo social até então vigente (modelo celular burguês), baseado na união estável de dois indivíduos coabitando o mesmo espaço e prometendo-se fidelidade absoluta pelo resto de suas vidas. Esses jovens têm testado outras formas, outros tipos de relacionamento que não se enquadram neste último modelito: ter filhos e criá-los sozinho; "morar" junto mas não casar, por exemplo. Vêse então uma alteração na forma e conteúdo da estrutura familiar que imperava. Não adianta a 'boa moral e os bons costumes' espernearem, não adianta a Igreja excomungar, ameaçar com a fogueira do inferno. Neste ponto da mudança, a coerção já não é eficaz, porque os jovens ou não assimilaram a 'razão' para manterem-se naquele modelo anterior ou, por outras motivações, questionam o "sentido" daquela instituição e dos valores e expectativas que a sustentam, pretendendo novos "sentidos", novos "desejos", novos "valores", logo, novas relações sociais. É assim a dialética instituição-indivíduo/ relação social-ação social.

\section{Impaciente com meus rodeios, ela volta à carga: - Mas e a criação de sentidos, há um momento exato para ela?}

Respondi que, como vinha dizendo, talvez não dê para achar a hora exata de nascimento de uma "motivação" qualquer para a ação humana. Seria possível descobrir em que momento exato uma parte dos jovens brasileiros 
resolveu considerar as drogas como um componente importante da sua experiência de juventude? Daria para saber exatamente quando as mulheres decidiram enfrentar o machismo? Talvez não dê. Embora dê para se aproximar dos inícios dessas novas tendências de comportamento, de suas primeiras manifestações, como, por exemplo, é plausível situar o marco da explosão do movimento feminista nos anos $60 \mathrm{~s}$, e dá até para tentar compreendê-las, tentando desvendar suas prováveis causas, a que tipo de expectativas responde. Para tanto, teríamos que questionar os agentes dessas mudanças para percebermos suas intenções, suas razões, seus motivos, como nos propõe Weber. E, nesse caso, podemos tentar vislumbrar se não há causas "externas" às intenções dos indivíduos, que ajudam a explicar o aparecimento e desenvolvimento dessas tendências novas.

Dou mais um exemplo: talvez o movimento feminista não tivesse, inicialmente, a intenção de romper, ao menos, com a estrutura - já não digo o mesmo quanto ao conteúdo - do modelo familiar anterior (maridomulher-filhos), mas o movimento conseguiu firmar novos espaços sociais para a mulher ampliando sua autonomia de vida. Esse componente (mais mulheres no mercado de trabalho; mais mulheres com estudo; mulheres menos coagidas pelos homens, etc.) pode ter facilitado/estimulado essas novas experiências de vida familiar, nas quais, por exemplo, a mulher cuida sozinha dos filhos, 'dispensando' o homem.

Um mercado de trabalho que abre oportunidades para as mulheres está, ao mesmo tempo, favorecendo aquelas novas experiências de vida associadas à maior autonomia sexual. O que quero dizer é que talvez teríamos aqui uma "variável causal externa" ao desejo dos agentes das novas experiências familiares. Noutros termos, sem esta variável poderiam não ocorrer tais experiências na quantidade relevante em que estão acontecendo. Não seria suficiente o desejo, a intenção, a expectativa das mulheres por novas formas de organização familiar se não pudessem dispor, por exemplo, de autonomia financeira, independência material em relação à família e a algum homem.

Ela insistiu, com um último pedido: Mostre-me um exemplo de produção de "sentido" para as ações, ou de 'razões para viver', que funcione hoje.

Disse-lhe: vou the mostrar uma "fonte de sentidos" para a vida de uma porção dos indivíduos que conhecemos. E é uma "fábrica de motivações" bastante poderosa. Peço-lhe licença para ler dois artigos que apresentam tal fábrica de valores. Um do Frei Betto e outro do jornalista Eugênio Bucci (ver no texto anterior). 